\title{
COMPREENSÕES DO ENSINO DE CIÊNCIAS NOS ANOS INICIAIS
}

\author{
UNDERSTANDING SCIENCE TEACHING IN THE EARLY YEARS
}

\author{
LUCAS MAXIMILIANO TOME \\ JOSIEL DE OLIVEIRA BATISTA ${ }^{2}$ \\ LUCIANE FERREIRA MOCROSKY ${ }^{3}$
}

\section{RESUMO}

Este artigo trata de uma pesquisa qualitativa fenomenológica, orientada pela interrogação "que compreensões o professor dos anos iniciais tem sobre Ciências e o seu ensino"? 0 trajeto foi de estudo bibliográfico documental do ensino de Ciências e dos professores dos anos iniciais do Ensino Fundamental, abrangendo aspectos da legislação e culminado com o discurso de professores atuantes em tal fase escolar. As falas revelam que os docentes no município investigado estão imersos num mar de desafios: 0 quadro não conta com professores especializado; a maioria são responsáveis por aulas de Educação Física e Ciências, dividindo seu tempo entre dois campos do saber; falta formação inicial e continuada; as exigências da alfabetização, leitura, escrita e operações com números, ficam na linha de frente. No ímpeto de ensinar, os docentes fazem escolhas que julgam pertinentes, passando longe do trabalho em alfabetização cientifica dos alunos, por não darem conta dela nem para si.

Palavras-chave: Ensino de Ciências. Anos iniciais. Formação do professor. Fenomenologia.

\section{ABSTRACT}

This article deals with a phenomenological qualitative research, guided by the question "what understandings do the teacher of the early years have about Science and its teaching"? The trajectory was a bibliographic documental study of Science teaching and teachers from the early years of Elementary School, covering aspects of legislation and culminating in the discourse of teachers working in this school phase. The statements reveal that the teachers in the investigated municipality are immersed in a sea of challenges: the staff does not have specialized teachers; most are responsible for Physical Education and Science classes, dividing their time between two fields of knowledge; lack of initial and continuing training; the demands of literacy, reading, writing, and number operations are at the forefront. In the drive to teach, teachers make choices they deem pertinent, going far from the work of students' scientific literacy, as they cannot handle it even for themselves.

Keywords: Science teaching. Initial years. Teacher Education. Phenomenology.

\section{RESUMEN}

Este artículo trata de una investigación cualitativa fenomenológica, guiada por la pregunta "¿qué entendimientos tiene el docente de los primeros años sobre la ciencia y su enseñanza"? La trayectoria fue un estudio documental bibliográfico de la docencia y el profesorado de las Ciencias desde los primeros años de la Escuela Primaria, abarcando aspectos de la legislación y culminando en el discurso de los profesores que laboran en esta etapa escolar. Los discursos revelan

\footnotetext{
1 Mestre em Educação em Ciência e em Matemática pela Universidade Federal do Paraná - UFPR. Docente no Centro de Treinamento Monte Horebe. E-mail: maximilianolucas@hotmail.com.br - ORCID: https://orcid.org/0000-0001-6809-8479

2 Doutorando em Educação em Ciência e em Matemática pela Universidade Federal do Paraná - UFPR. Docente na Universidade Federal do Sul e Sudeste do Pará - Unifesspa. E-mail: josieloliveira@unifesspa.edu.br - ORCID: https://orcid.org/ 0000-0002-3030-8992

3 Doutorado em Educação Matemática pela Universidade Estadual Paulista "Júlio de Mesquita Filho" - UNESP/Rio Claro - SP. Docente na Universidade Tecnológica Federal do Paraná - UTFPR. E-mail: mocrosky@gmail.com - ORCID: https://orcid.org/ 0000-0002-8578-1496
} 
que los docentes del municipio investigado están inmersos en un mar de desafíos: la junta no cuenta con profesores especializados; la mayoría son responsables de las clases de Educación Física y Ciencias, dividiendo su tiempo entre dos áreas de conocimiento; falta de formación inicial y continua; las demandas de alfabetización, lectura, escritura y operaciones numéricas están a la vanguardia. En el impulso de enseñar, los profesores toman las decisiones que consideran pertinentes, alejándose del trabajo de alfabetización científica de los estudiantes, ya que no pueden manejarlo ni siquiera por sí mismos.

Palabras-clave: Enseñanza de las ciencias. Años iniciales. Formación de profesores. Fenomenología.

\section{CONSIDERAÇÕES INICIAIS}

Este artigo é fruto de uma pesquisa qualitativa desenvolvida no Grupo de Estudos e Pesquisa em Formação de Professores (GEForProf), realizada em 2019, assumindo a postura fenomenológica. Dada a experiência dos autores no ensino de Ciência na Educação Básica, assim como em cursos de formação de professores, que vêm revelando fragilidades no ensino de Ciências, busca explicitar as inquietações e reflexões que se mostraram nos assuntos que enredam o ensino de Ciências nos anos iniciais. Destas inquietações, permanece pulsando em nossos estudos a interrogação: que compreensões o professor dos anos iniciais tem sobre Ciências e o seu ensino?

Na esteira das vivências de professores que ensinam Ciências, expomos este estudo pelas lentes do primeiro autor (TOMÉ, 2019), ao longo da sua trajetória profissional, e apontamos nossas contribuições que se dão na relação orientadora e orientandos. Essa caminhada elucidou que a docência solicita o preparo para enfrentar muitos desafios que ocorrem dentro e fora de uma sala de aula e que, muitas vezes, de longe tangem os conteúdos escolares (SILVA, 2018).

É certo que nos anos iniciais o ensino de Ciências, como disciplina, não avança teoricamente nos conteúdos de ensino, mas prepara o solo no qual aluno e professor se lançam às elaborações. Filho et.al. (2012, p. 05) deixam claro, contudo, que, nos anos iniciais, o ensino de Ciências "deverá propiciar a todos os cidadãos os conhecimentos e oportunidades de desenvolvimento de capacidades necessárias para se orientarem nesta sociedade complexa, compreendendo o que se passa à sua volta, tomando posição e intervindo na sua realidade".

É perceptível a relevância de se olhar mais atentamente para esse professor, notadamente sobre como ele, que está em sala de aula, compreende o ensinar Ciências nos anos iniciais. Carvalho (1997, p. 154) descreve que "0 ensino de Ciências, nessas primeiras etapas do Ensino Fundamental, tem a obrigação de dar o primeiro passo com os alunos na caminhada que os levará dos conceitos espontâneos aos conceitos científicos. 0 professor deve estar preparado para esta sistematização".

Mas, quem é este professor que está em sala de aula? Como ele se constitui professor de Ciências para as crianças? Que compreensões ele revela sobre a (sua) ação docente? Como ele é formado e se lança para permanecer em formação no exercício da docência?

Estas perguntas abriram um horizonte para a pesquisa que teve em destaque a Ciência-e-seu-ensino-nos-anos-iniciais ${ }^{4}$ como fenômeno a ser investigado. Fenômeno entendido pela fenomenologia como 0 que se mostra, como o que se destaca de um fundo inquiridor e que só pode ser assim constituído se existir um sujeito que o vivencia. Fenômeno não é um fato, mas antes 0 que vem das perplexidades e nos convida a ir à busca de novas perspectivas, escavando o desconhecido pelo que dele se conhece, pelo que se mostra. 0 fenômeno é muito mais o que não aparece naquilo que se

40 uso do hífen tem como intuito reforçar que não estamos atentos somente às Ciências, mas também para 0 ensino de Ciências nos primeiros anos de escolaridade. Sendo assim, Ciências, ensino, anos iniciais, não podem ser vistos isoladamente, mas como partes de um todo. 
mostra, ou seja, é o que "se mantém velado frente ao que se mostra diretamente e na maioria das vezes, mas, ao mesmo tempo, permanece essencialmente ao que se mostra diretamente [...] a ponto de constituir o seu sentido e fundamento" (HEIDEGGER, 1999, p. 66).

Este estudo que nasceu de inquietações de professores formadores de professores de Ciências para os anos iniciais se orientou pela interrogação: que compreensões o professor dos anos iniciais tem sobre Ciências e o seu ensino? e foi ao encontro de docentes dos anos iniciais, que têm a incumbência de realizar tal ensino.

\section{O ENSINO DE CIÊNCIAS PAUTADO EM DOCUMENTOS OFICIAIS: UM BREVE DIÁLOGO SOBRE ESTE ENSINO NA CONTEMPORANEIDADE}

Ao buscarmos por compreensões sobre o que é o ensino de Ciências nos anos iniciais da Educação Básica, orientado pela interrogação: que compreensões o professor dos anos iniciais tem sobre Ciências e o seu Ensino? o primeiro passo foi ir aos documentos que subsidiam o ensino de Ciências nos anos iniciais, como as Diretrizes Curriculares da Educação Básica (DCE), Parâmetros Curriculares Nacionais do ensino de Ciências (PCN), a Lei de Diretrizes e Bases da Educação (LDB), a Base Nacional Comum Curricular (BNCC), dentre outros. Buscamos, com a leitura atenta desses documentos, saber o que dizem sobre o ensino de Ciências nos primeiros anos de escolaridade, sobre a formação dos professores que ensinam Ciências e como se estrutura tal ensino.

Sabemos que a sistematização do conhecimento científico vem acompanhando as evoluções pela observação da natureza de um modo integrado com repercussões sociais, econômicas, éticas e políticas, ou seja, trata-se um conhecimento que proporciona ao ser humano o desenvolvimento de uma cultura científica. Essa cultura vem sendo implantada ao longo do Ensino Fundamental, na área de Ciências da Natureza que "tem um compromisso com o desenvolvimento do letramento científico, que envolve a capacidade de compreender e interpretar o mundo (natural, social e tecnológico), mas também de transformá-lo com base nos aportes teóricos e processuais das ciências" (BRASIL, 2018, p. 321 - grifo do autor).

No que se refere especificamente à disciplina escolar de Ciências, segundo o documento em discussão, tal disciplina iniciou sua consolidação no currículo das escolas brasileiras em 1931 com a Reforma Francisco Campos e objetivava "transmitir conhecimentos científicos provenientes de diferentes Ciências naturais de referência já consolidadas no currículo escolar brasileiro" (PARANÁ, 2008, p. 51). Nesse momento histórico era fundamental um ensino de Ciências sintonizado com o progresso nacional. Para tanto, a disciplina de Ciências era orientada por metodologias que enfatizavam a memorização de fatos e de cientistas importantes, uma vez que se objetivava divulgar as descobertas científicas. Assim, priorizava-se a quantidade de informações em detrimento de abordagens mais investigativas.

Já na década de 1940, com Reforma Capanema, o ensino passava a objetivar uma "elite condutora" e a legislação endossava claramente esse aspecto de divisão de classes a partir dos anos iniciais da escolarização e o currículo organizava o ensino secundário em dois ciclos (primeiro de quatro anos e 0 segundo de três anos). "Em linhas gerais, no $3^{0}$ ano, atual $7^{a}$ série do Ensino Fundamental, abordava-se os seguintes conteúdos: água, ar e solo, noções de botânica e de zoologia e corpo humano. No $4^{0}$ ano, atual $8^{a}$ série do Ensino Fundamental, prevaleceram as noções de Química e Física" (PARANÁ, 2008, p. 71).

Com a modernização do Brasil, surgiu a necessidade de qualificação da mão de obra, ou seja, as exigências sociais passavam a influenciar o modo como se organizava os currículos, buscando 
atender a demanda, contexto esse em que surge o IBECC (Instituto Brasileiro de Educação, Ciências e Cultura), instituição vinculada à UNESCO (Organização das Nações Unidas para a Educação, a Ciências e a Cultura) em 1946. Tal instituição tinha como objetivo melhorar a formação científica dos estudantes brasileiros (KRASILCHIK, 2000).

Na década seguinte, seguindo tendências mundiais de atualização tecnológica, em que Ciências e Tecnologia passavam a ser reconhecidas como atividades essenciais no desenvolvimento econômico, cultural e social, houve outro momento de transformação no contexto escolar. Nesse momento o objetivo era guiado pela necessidade do conhecimento científico com vistas à superação da dependência tecnológica que o Brasil apresentava.

No entanto, sob a forte influência europeia, na década de 1960, os projetos que chegavam ao Brasil em forma de políticas governamentais traziam uma concepção de Ciências neutra e eram centrados em uma visão de educação científica que procurava promover a reprodução de modelos científicos por meio da experimentação. Portanto, em se tratando de objetivos à disciplina de Ciências, é possível vislumbrar uma mudança no que se pretende fomentar para a formação dos estudantes, a saber, formar estudantes que se mostravam mais capazes para atuar no progresso da Ciência e da Tecnologia brasileiras (KRASILCHIK, 2000).

Ainda na década de 1960, com a LDB nº. 4024/61, é consolidado o ensino de Ciências no currículo escolar, sendo obrigatória nos anos finais do Ensino Fundamental, objetivando preparar os estudantes em prol da defesa do progresso da Ciência e Tecnologia do país, a partir de aulas centradas na experimentação e reprodução dos modelos científicos (BRASIL, 1961).

Desse modo, constata-se que a disciplina de Ciências em nosso país é relativamente nova nas salas de aula e vem sendo movimentada pelos "diferentes interesses econômicos, políticos e sociais sobre a escola básica e dos avanços na produção do conhecimento científico" (PARANÁ, 2008, p. 64). Nesse sentido, o que se objetiva com sua inserção nas salas de aulas também segue as mudanças sociais e culturais, ou seja, o sentido orientador vai se movimentando. Inicialmente, enfatiza-se a memorização, passando a um caráter propedêutico, preliminar, introdutório, algo que serve de acesso, chegando à priorização de promover uma formação científica dos estudantes, no entanto, ainda voltada à elite e pautada na meritocracia.

Só na década de 1970, sob o impacto da revolução técnico-científica, as questões ambientais decorrentes da industrialização desencadearam uma nova concepção sobre o ensino de Ciências e dá-se início à discussão quanto as implicações sociais do desenvolvimento tecnológico e científico. Nesse contexto, em 1971 implementa-se a LDB n. 5692/71 (BRASIL, 1971).

Tal lei apresentou grandes mudanças no ensino de Ciências enfatizando a integração da disciplina em todas as séries do Ensino Fundamental. Passa-se a valorizar uma estrutura integrada não apenas no sentido de sua horizontalidade ao longo dos anos do Ensino Fundamental, como também, há a formalização dos eixos de ensino: "1. Noções de Astronomia; 2. Transformação e Interação de Matéria e Energia; e 3. Saúde - melhoria da qualidade de vida" (PARANÁ, 2008, p. 55). Assim, 0 que se passa a objetivar é a oferta ao aluno de proporcionar habilidades para que possa compreender 0 mundo. Além do que, essa divisão se dá pela importância da não sequência dos assuntos, mas sim, relações com os temas estudados.

Em 1996, com a promulgação da LDB no 9394, "foram produzidos os Parâmetros Curriculares Nacionais (PCN) que propunham uma nova organização curricular em âmbito federal" (PARANÁ, 2008, p. 55). Essa organização fez com que o currículo para a disciplina de Ciências, do Estado 
do Paraná, fosse organizado pelos novos eixos temáticos: "1. Terra e Universo; 2. Vida e Ambiente; 3. Ser humano e Saúde; e, 4. Tecnologia e Sociedade" (PARANÁ, 2008, p. 56).

Segundo os PCN (1997), devido à ampla relação entre os conteúdos, se faz necessário estabelecer alguns critérios para selecionar determinados temas a serem estudados, como:

$1^{0}$ Os conteúdos sejam compatíveis com o nível intelectual do aluno de maneira que ele possa agir criticamente e possa progredir em seus conhecimentos; $2^{\circ}$ Os conteúdos devem proporcionar uma visão do mundo, correlacionando o homem, agente de transformação, os fenômenos naturais e a tecnologia; $3^{\circ}$ Devem ser relevantes ao seu meio social, permitindo 0 aluno a assimilar os conceitos e a realidade a sua volta (BRASIL, 1997, p. 33).

Essa estruturação, por blocos temáticos, objetiva auxiliar o professor a "criar e organizar seu planejamento considerando sua realidade" (BRASIL, 1997, p. 34).

Nos PCN há a descrição de que o conhecimento científico nos anos iniciais é relevante pelo fato de se estar em uma era com uma crescente evolução tecnológica e a valorização deste estudo. É a disciplina de Ciências Naturais que abre espaço para as diversas respostas sobre o planeta, os fenômenos, o homem, as transformações da natureza e os incontáveis produtos científicos existentes, devido a disciplina escolar convergir diretamente para o meio que relaciona a Astronomia, Biologia, Física, Geociências e a Química (BRASIL, 1997). Desse modo, cabe ao ser humano interpretar os fenômenos apresentados pela natureza, tais como "tempo, espaço, matéria, movimento, força, campo, energia e vida" (PARANÁ, 2008, p. 40).

0 primeiro contato com os conteúdos de Ciências nos anos iniciais, tal como o observado nos PCN, traz a ideia de explorar, conhecer e explicar situações e fenômenos articulando a noções iniciais mais próximas a Ciências. Além disso, traz também a articulação com o processo de alfabetização dos estudantes: "não se trata somente de ensinar a ler e a escrever para que os alunos possam aprender Ciências, mas também de fazer usos das Ciências para que os alunos possam aprender a ler e a escrever" (BRASIL, 1997, p. 45).

Assim, entende-se que é nos anos iniciais que se dá a abertura para a construção deste pensamento questionador e a formação de um cidadão crítico, pois a "criança não é cidadã do futuro, mas já é cidadã hoje e, nesse sentido, conhecer Ciências é ampliar a sua possibilidade presente de participação social e viabilizar sua capacidade plena de participação social no futuro" (BRASIL, 1997, p. 23).

A estruturação de um pensamento científico na disciplina de Ciências Naturais, segundo os PCN, se faz gradativamente de modo que nos primeiros anos do Ensino Fundamental se "constrói repertórios de imagens, fatos e noções, sendo que o estabelecimento dos conceitos cientííicos se configura nos ciclos finais" (BRASIL, 1997, p. 28). Ou seja, o ensino de Ciências passa a ter a função de preparar 0 aluno para promover um avanço significativo ano após ano, construindo e até mesmo desconstruindo os conceitos errôneos.

Outro aspecto é "onde" se começa esse ensino? Começa muito antes do contato com a escola. Por isso, "aprendizado e desenvolvimento estão inter-relacionados desde o primeiro dia de vida e qualquer situação de aprendizagem na escola tem sempre uma história anterior" (PARANÁ, 2008, p. 58), de modo que nas aulas de Ciências Naturais passa-se a ser essencial debater, investigar os fatos, desenvolver experimentos, escrever textos, desenhar, montar gráficos e esquemas. Tratar dos diferentes recursos e estratégias didáticas para dinamizar o ensino de Ciências apontam para a necessidade de 
em um processo satisfatório que envolva não apenas o conceito em si, mas sua aplicação no cotidiano, instigando 0 aluno a ser um cidadão formador de opiniões (BRASIL, 1997; PARANÁ, 2008).

Assim, ressalta-se que no ensino de Ciências com base na leitura de seus documentos norteadores, há uma preocupação com a valorização dos conhecimentos prévios e suas relações com 0 cotidiano dos estudantes como ponto de partida para a construção do conhecimento científico.

A perspectiva de eixos na organização da disciplina escolar demonstra a preocupação com a superação da fragmentação dos conteúdos, bem como traz a discussão de uma concepção de Ciências dinâmica, articulada e crescente conforme a divisão por anos da escolarização. 0 que se busca é 0 favorecimento de um estudo de forma dinâmica, bem como se tem a possibilidade de se estruturar um modo de pensar científico desde os anos iniciais, partindo das vivências e dos conhecimentos prévios dos estudantes. Stoll et al. (2021), com base em Delizoicov (1991) ressaltam a importância do desenvolvimento do pensamento científico pautado em metodologias que enfatizem a experimentação. Segundo os autores, "essa metodologia, quando empregada de forma contextualizada, problematizada e com objetivos bem definidos, pode contribuir para emancipação do pensamento científico" (STOLL, et al. 2021, p. 95). Afirmam também que seu emprego pode trazer vantagens como "autonomia na formulação de hipóteses; construção de ideias entre os pares; desenvolvimento argumentativo; e melhoria nas interações intelectuais, físicas e sociais" (p. 95).

Na atualidade, a elaboração de um documento balizador e integrador para a Educação Básica, reformula o ensino voltado para a área das Ciências da Natureza ao compreender a Ciência pelo viés do letramento científico, ou seja, "apreender ciência não é a finalidade última do letramento, mas, sim, o desenvolvimento da capacidade de atuação no e sobre o mundo, importante ao exercício pleno da cidadania" (BRASIL, 2018, p. 321).

A BNCC pressupõe a organização de situações de aprendizagem, tendo como foco a formação do estudante pautada no processo formativo, por meio de situações didáticas que transversalizam toda a Educação Básica, "partindo de questões que sejam desafiadoras e, reconhecendo a diversidade cultural, estimulem 0 interesse e a curiosidade científica dos alunos e possibilitem definir problemas, levantar, analisar e representar resultados; comunicar conclusões e propor intervenções" (BRASIL, 2017, p. 322).

Esses avanços na estrutura curricular levam ao questionamento: o que os estudiosos da área dizem sobre essas mudanças e de que forma elas inovaram o ensino da disciplina? Qual foi a novidade trazida para a função desse profissional que atua como mediador do conhecimento científico na disciplina escolar de Ciências?

\section{ANUNCIANDO OS PROCEDIMENTOS DA PESQUISA}

Este estudo, de cunho qualitativo fenomenológico, foi orientado pela interrogação "que compreensões o professor dos anos iniciais tem sobre Ciências e o seu ensino?", que solicitou ir ao encontro de professores atuantes nos anos iniciais, ensinando ciências às crianças. Bicudo (2011) explicita que a pesquisa qualitativa com abordagem fenomenológica visa compreender o fenômeno destacado no amplo campo de interesse do investigador, ao interrogá-lo, atentos aos seus modos de aparecer. Portanto, trata-se de uma postura adotada, que tem na pesquisa qualitativa um modo autêntico de pesquisar e de ler o mundo. Considerando que o fenômeno é perspectival e que a compreensão dele "não se esgota nunca" (FINI, 1994, p. 24), não há a pretensão de provar/validar quaisquer 
proposições no presente trabalho e sim de descrever como o fenômeno foi sendo desvelado e refletir sobre 0 visto no encontro pesquisadores-interrogação-professores.

Para encontrar os possíveis participantes da pesquisa, entramos em contato com cinco escolas de uma cidade da região metropolitana de Curitiba, por contextualizar a experiência vivida de um dos autores, para conhecer aquelas que se mostrariam abertas a participar do estudo. Das cinco escolas contatadas, obtivemos retorno de quatro. Num encontro previamente agendado esclarecemos aos interessados (direção e professores) sobre os objetivos do estudo, modos de proceder da pesquisa, tempo estimado de trabalho e confidencialidade dos dados. Assim, marcamos o compromisso, recoIhendo assinaturas de concordância em participar do estudo.

Ao constatar que os professores realizavam a hora-atividade concentrada com seus pares, este foi 0 momento de encontro com os docentes de Ciências em cada uma das escolas. Com hora marcada e no próprio ambiente de trabalho, nos reunimos solicitando que em conjunto, quando a escola tinha mais de um professor de ciência, falassem livremente em atenção à pergunta "como 0 senhor(a) compreende 0 ensino de Ciências para as crianças, ou seja, nos anos iniciais do Ensino Fundamental?", dialogando com seus pares, sem a intervenção de novas perguntas que pudessem direcionar respostas.

Em duplas ou individualmente ouvimos 13 (treze) professores ${ }^{5}$, gravando em áudio os depoimentos individuais ou coletivos. Ao discursarem livremente não nos preocupamos com o tempo de cada encontro, que findou quando os professores repetiam ideias e sentiam que já havia esgotado os modos de responder. Ouvimos os depoimentos muitas vezes para transcrevê-los, captando as falas para obter as expressões o mais próximo possível do dito, registrando também as entonações, que revelam sobre 0 falado, identificando os participantes por P1 até P13.

Esclarecemos aos leitores da Revista Vidya que para o desenvolvimento desta pesquisa não foi solicitada prévia avaliação ética pelo Sistema CEP/CONEP, conforme solicitado pela presente revista, devido ao fato de o programa de pós-graduação ao qual os autores estão vinculados não possuir, no momento do desenvolvimento do estudo, comitê constituído. Entretanto, tomamos o cuidado ético de elaborarmos, antes da realização da pesquisa, um Termo de Consentimento Livre e Esclarecido que foi assinado pelos participantes, com o objetivo de conscientizá-los acerca das ações e intenções da pesquisa. Foram, ainda, seguidos todos os preceitos éticos respeitando as normas da resolução $n^{0}$ 466/2012 do Conselho Nacional de Saúde. Deste modo, nos responsabilizamos por qualquer eventual dano resultante a quaisquer dos participantes, de acordo com a Resolução $\mathrm{n}^{0} 510$, de 7 de abril de 2016, do Conselho Nacional de Saúde, eximindo a Revista Vidya de qualquer responsabilidade.

Após as transcrições, iniciamos as análises do dito, à luz do perguntado, efetuando o movimento de redução fenomenológica. Esta, consiste no "ato de colocar em evidência o foco de investigação, visando destacar o que está sendo interrogado, de maneira que os atos da consciência constitutivos da geração de conhecimento sejam expostos" (BICUD0, 2011, p. 35).

Num primeiro momento da redução, destacam-se as Unidades de Significado (US). Estas são recortes dos textos sobre o que vem dizendo do perguntado, analisados à luz da hermenêutica. Esse movimento foi realizado com todos os depoimentos e se pautou nas particularidades de cada discurso, nas ideias individuais de cada sujeito, caracterizando o movimento analítico-reflexivo da Análise Ideográfica (AI), revelando a interpretação dada ao fenômeno interrogado na individualidade de cada discurso (BATISTA, MOCROSKY e MONDINI, 2019, p. 4).

Nesse processo analítico-interpretativo, os dados são escritos na linguagem do pesquisador, possibilitados pela interpretação/compreensão das expressões espontâneas dos professores participantes

50 s 13 (treze) professores representam aqueles que estavam em sua hora atividade na escola no dia da entrevista. 
da pesquisa. Esse movimento da fala articulada é o momento em que o pesquisador apresenta a sua linguagem, o mais claro possível, realizando a análise interpretativa. 0 pesquisador coloca-se "pensando sobre o compreendido e vai articulando isso que está fazendo sentido e o que emerge do diálogo mantido [...] respondendo a interrogação" (BICUDO, 2018, p. 246).

Seguindo o movimento analítico-reflexivo da redução fenomenológica, após a transcrição dos depoimentos, destaque das US e respectivas escritas na linguagem do pesquisador, a ação foi de voltar em cada uma das US reescritas pelos investigadores, buscando entender o que estaria no centro dessa fala, procurando destacar as Ideias Nucleares (IN).

Em síntese, 57 US convergiram para 6 IN: I.1 - Importância do ensino de Ciências, I.2 - Dificuldade de ensinar Ciências, I.3 - Tempo para o ensino, I.4 - Estratégia de ensino, I.5 - Planejamento curricular de Ciências, I.6 - Afinidade docente com a disciplina escolar. Estas guiaram a pesquisa para um novo movimento de redução, a Análise Nomotética (AN). Esse é momento em que a pesquisa inicia a passagem do individual ao geral, ou seja, da análise ideográfica para a nomotética.

A AN é caracterizada pela busca de generalizações que surgem a partir das convergências ou divergências advindas dos depoimentos. Esse procedimento é feito "efetuando uma metacompreensão de toda trajetória e do que foi se clareando para o pesquisador em termos do interrogado" (BICUDO, 2011, p. 66) com 0 intuito de desaguar em grandes regiões de generalidades do fenômeno em estudo. Tais regiões são aqui denominadas de Categorias Abertas (CA) e articulam as IN advindas da US, por meio do trabalho hermenêutico realizado.

As CA mostram a estrutura do fenômeno estudado. São assim denominadas, "pois não definem a estrutura do ser por categorias, mas revelam as categorias articuladas no processo de investigação mediante as análises ideográficas e nomotética, abrindo-se ao trabalho hermenêutico, revelando possíveis horizontes de compreensões em movimentos de vir a ser" (BICUD0, 2011, p. 66).

Neste estudo, trazemos para discussão uma das duas categorias abertas evidenciadas no estudo, que nomeia este artigo (TOMÉ, 2019), a saber: compreensões do ensino de Ciências nos anos Iniciais.

\section{COMPREENSÕES DO ENSINO DE CIÊNCIAS NOS ANOS INICIAIS}

No encontro com professores que ensinam Ciências nos anos iniciais, ao indagarmos sobre Ciências-e-o-seu-ensino-nos-anos-iniciais à luz da pergunta disparadora dos diálogos com os professores: como o senhor(a) compreende o ensino de Ciências para as crianças, ou seja, nos anos iniciais do Ensino Fundamental? retomamos diversas vezes nas falas dos depoentes dando atenção ao que estava se revelando sobre o interrogado. Nesse movimento de análise, quatro ideias nucleares I.1, I.3, I.4 e I.5, se destacaram e compuseram a categoria Compreensões do ensino de Ciências nos Anos Iniciais.

Na dinâmica das análises, um dos primeiros aspectos que nos chamou atenção foi a formação apresentada pelos professores. A grande maioria é formada por graduados em Pedagogia (como recomenda a DCE) e até o momento do encontro ocorrido para a produção dos dados, nenhum tinha realizado estudos específicos, como uma especialização para lecionar a disciplina de Ciências.

Os docentes, ao relatarem sobre suas experiências vividas em sala de aula, orientam-se com uma especial atenção no eixo temático "Vida e Ambiente", como descrito por P3: "daí nós também trabalhamos bastante, né, voltado pro meio ambiente que é uma coisa que tá, né, englobado nas Ciências que é de grande importância para nós e pro nosso ambiente" (2019); assim como para o eixo "Ser Humano e Saúde", como relatado por P1: "vejo que, além de importante o ensino da 
Ciências ele desenvolve bastante as crianças. Ele ajuda bastante 0 conhecimento geral da criança no seu dia a dia, do funcionamento do corpo, do organismo" (2019).

Outros professores destacam a Importância do ensino de Ciência de uma forma mais holística. Quando relatam que ensinar Ciências é entender o corpo, meio ambiente e o mundo ao seu redor. Fica evidente a preocupação com o ensino em Ciências e sua articulação ao cotidiano dos estudantes. Mesmo que este ensino se dê mais fortemente pelo tema Meio Ambiente é possível o entendimento, de que este auxilia na formação do cidadão. P10 afirma:

[...] hoje em dia 0 estudo das Ciências, ele é voltado para ensinar as crianças a entenderem melhor o mundo e aproximar elas da ideia da preservação ambiental, que é o foco hoje em dia da nossa disciplina. Explica o mundo, ajuda a pensar, ajuda elas a entenderem essa ideia da preservação, ela abrange várias áreas (P10, 2019).

De modo mais amplo, Filho, Santana e Campos (2011) ancorados em Fumagalli (1998) afirmam que 0 ensino de Ciências é responsável pela promoção de uma formação integral de um cidadão, responsável, pensante e atuante na sociedade, de modo que o ensino vise três sentidos: "(a) A Ciência como corpo conceitual de conhecimentos, como sistema conceitual organizado de forma lógica; (b) Ciência como forma de produção de conhecimentos e; (c) Ciência como modalidade de vínculo com 0 saber e sua produção" (FUMAGALLI, 1998, p. 20).

Ao dialogarmos com essa visão mais ampla do que se constitui o ensino de Ciências e 0 que nos dizem os depoentes, nos questionamos sobre a intensidade como o tema Meio Ambiente apresentou-se. Desse modo, ensinar Ciências é apenas trabalhar com as questões ambientais?

A esse respeito Fabri e Silveira (2012) mencionam que o eixo temático Meio Ambiente, apresentado pelos PCN, precisa ser trabalhado pelos professores em todas as etapas da Educação Básica. É de sua responsabilidade direcionar atividades que contemplem a preservação ambiental em diversas direções, sendo assim, um eixo articulador de conhecimentos sobre Ciências e para a Ciência.

0 dito pelos autores se presentifica nos dias atuais ao ir ao encontro do descrito na BNCC, por meio do campo de experiência "espaços, tempos, quantidades, relações e transformações" definido como um elemento balizador e indicativo para a constituição do ensino na Educação Infantil. Esse elemento é apresentado desde a primeira etapa da educação formal e se torna presente na transição da Educação Infantil para o Ensino Fundamental ao colocar como objetivo dessa etapa "interagir com o meio ambiente e com fenômenos naturais ou artificiais, demonstrando curiosidade e cuidado com relação a eles" (BRASIL, 2018, p. 55).

Desse modo, os alunos precisam conhecer os fenômenos para poder se manifestar, pois "a Ciência e a Tecnologia, ao mesmo tempo em que podem ser usadas para facilitar a vida das pessoas, podem se tornar uma ameaça gerando sérios problemas ambientais e sociais" (FABRI, SILVEIRA, 2012, p. 102). Os autores explicitam a importância do papel do professor para desenvolver atividades diversificadas de modo a tematizar meio ambiente para que este envolva aspectos que favoreçam 0 reconhecimento da individualidade na construção da humanidade. Isso porque

P10: [...] hoje em dia nós trabalhamos [...] muito voltado ao meio ambiente, aos quesitos de preservação e, é isso. [...] 0 mundo como um todo desde a ideia da criação [...], a Ciências vem desde o começo do mundo até a gente trabalha os estados físicos da água, essas coisas. É fácil de ensinar [...] e ajuda as crianças no cotidiano dela e na conscientização como formação de cidadão, de... de ser humano (2019). 
Carvalho (1997), Fumagalli (1998), Lorenzetti (2000), Bizzo (2002), Filho, Santana e Campos (2011) chamam a atenção para outro ponto de vista, esclarecendo que os anos iniciais é a etapa na qual os alunos trazem muitos conhecimentos espontâneos sobre diversos assuntos. Claramente, não é só nos anos iniciais que os alunos os apresentam, mas em todas os momentos da Educação Básica. Porém, esta etapa dos anos iniciais é marcada por movimentos formativos em que a criança constrói e reelabora seus modos de ver o mundo, de se reconhecer como construtor humano, sempre junto com os outros e no meio em que vive, responsável pelas realizações.

Entendemos também que ensinar uma disciplina com uma pluralidade de conteúdos não é uma tarefa simples. Bizzo (2002) esclarece que o professor precisa estar sempre em formação, cuidando da sua bagagem conceitual no horizonte da sua profissão: ensinar Ciências às crianças. Talvez um primeiro caminho que se abra a investigar mais sobre como o professor dos anos iniciais compreende 0 ensino de Ciências nos anos iniciais, precisaria passar por um reconhecimento de que "existem muitas dúvidas sobre como ensinar Ciências e que o número de perguntas é muito maior do que 0 de respostas" (BIZZO, 2002, p. 14).

Não apenas viver em sociedade, o entendimento que se faz é de que Ciências contribui com a elaboração de argumentos para questionar os reflexos da ação humana ao seu redor. Entretanto, mesmo a disciplina apresentando características sólidas de sua importância em nosso meio, o que se constata nos depoimentos é a prevalência de outras unidades curriculares na rotina da escola. Sobre isso P3 declara:

infelizmente a Ciências vai ficando mesmo em segundo plano porque é muito extenso o planejamento pra você cumprir. $E$, falando a verdade as crianças chegam muitas vezes no $5^{0}$ ano com aquela dificuldade lá: ler, interpretar e tudo, e na Matemática também. Então você foca mais (P3, 2019).

Ao buscarmos os motivos que podem estar levando a esse fenômeno de colocar em segundo plano 0 ensino de Ciências nos anos iniciais, observamos os depoimentos de P4 e P6 convergindo para os mesmos motivos: a necessidade de ensinar a ler, escrever, contar...

P4: [...] eu trabalho mais o Português e Matemática porque eles têm que chegar no final do ano e sair alfabetizado, né? Lendo e escrevendo (2019).

P6: Nós focamos no Português e Matemática. Então a Ciências a gente dá uma passada, mas a gente foca mesmo é no Português e Matemática. Aonde eles estão? Na leitura, eles estão descobrindo o mundo da leitura e isso é na leitura e na escrita (2019).

As ideias expostas nestes recortes mostram compreensões de que, mesmo reconhecendo 0 valor do ensino de Ciências, a prioridade e o desafio de lecionar Ciências recai sobre dois núcleos formativos: Matemática e Língua Portuguesa. Isso porque, entendem que sem os conhecimentos básicos de leitura e escrita não seja possível aprender outros conteúdos. Isso mostra uma concepção de ensino arraigada em valores escalonados, onde algumas disciplinas escolares formam o núcleo relevante, deixando a compreensão de que só se aprende Ciências se souber ler, escrever, reconhecer vocabulário numérico e com estes operar.

Sobre isso Fumagalli (1998) desde os anos 1990 vem alertando: "na prática cotidiana de nossas escolas [...] continua-se dando prioridade ao ensino das chamadas "matérias instrumentais" (Matemática e linguagem), [...] principalmente na primeira e segunda séries[...]" (p. 14-15). Filho, Santana e 
Campos (2011), vão ao encontro de Fumagalli (1998), afirmando que existe uma diversidade de assuntos a serem tratados no ensino de Ciências, visto que o professor pode trabalhar com inovações, experimentos e descobertas com as crianças. Contudo, essa disciplina não é tão explorada perante os professores, pois priorizam um modo estreito de conceber alfabetização, ao invés de ir à busca de articulações possíveis entre disciplinas escolares, para conquistar os alunos e trabalhar essa diversidade de conteúdos elencados nos programas.

A literatura vem mostrando que esses professores polivalentes, "responsáveis pelas disciplinas básicas do Ensino Fundamental - Língua Portuguesa, Matemática, Ciências, História e Geografia" (DUCATTI-SILVA, 2005, p. 33) recorrem para a alfabetização, devido ao fato da imposição da sociedade pensar que escola de qualidade é aquela que ensina muito bem a criança os saberes oriundos da Língua Portuguesa e Matemática (GEGLIO, 2015).

A visão expressa pelos professores sobre alfabetização se reduz ao reconhecimento do alfabeto, leituras e operações aritméticas, sem levar em conta avanços da criança na "compreensão de si, no mundo que a circunda". Conforme estudos de Andrade e Mocrosky (2018, p. 1-2), o que se mostra pertinente aos anos iniciais, quando se fala em alfabetização, seria a possibilidade e "importância de um ensino articulador entre matemática, Ciências naturais e humanas e Língua Portuguesa, como solo da formação escolar". 0 deixar de lado 0 ensino de Ciências ganha ainda mais destaque quando os professores do primeiro ciclo ( $\left(1^{\circ}\right.$ e $2^{\circ}$ anos) nos dizem que "a gente trabalha, a gente trabalha, mas a gente não foca assim" (P6, 2019); ou "não toda a semana sabe? Você pega aquilo faz aquele trabalhão, põe na parede lá, mas não toda a semana trabalhando Ciências" (P7, 2019).

Os fios que vêm tecendo essa categoria colocam os conteúdos e 0 tempo para trabalho pedagógico como os fins da educação escolar. Há um coro sendo entoado: é preciso cumprir o programa daquilo que gera elementos para a avaliação em larga escala, sendo assim, o tempo de ensino deve ser gasto com isso. Disso decorre a segunda ideia nuclear que dá sustento a essa categoria: o Tempo para o Ensino.

Os depoimentos dos professores já evidenciaram que Ciências, como disciplina escolar, tem sido negligenciada pela quantidade de conteúdos entendidos no núcleo da alfabetização: Língua Portuguesa e Matemática. Assim, não dizem que a desconsideram na rotina escolar os conteúdos de Ciências, mas que o fazem em momentos que julgam oportuno, como um adendo ao ensino.

Esse modo de ser docente traz a angústia sobre o tempo dedicado às aulas de Ciências. Os professores falam da tomada de decisão pelo que julgam central para o ensino que produza resultados mensuráveis para a escola como instituição avaliada por programas específicos. Entretanto, mostram-se desconfortáveis em agir assim. Alguns depoentes ao falarem, iam perguntando a si mesmos sobre as orientações legais, insinuando que se os documentos oficiais exigissem declaradamente parte da carga horária para os conteúdos de Ciências Naturais, estes seriam ofertados e aí caberia 0 cumprimento do prescrito.

Analisando aspectos legais, na Lei de Diretrizes e Bases (LDB), 9394/96, o Art. 34 estabelece que "a jornada escolar no Ensino Fundamental incluirá pelo menos quatro horas de trabalho efetivo em sala de aula, sendo progressivamente ampliado o período de permanência na escola" (BRASIL, 1996, p. 18) ficando à critério do professor organizar em seu planejamento o tempo disponível para seu trabalho pedagógico respeitando as abordagens a serem estabelecidas e os conteúdos estruturantes abordados (PARANÁ, 2008).

Os documentos deixam claro a inexistência da obrigatoriedade de um tempo mínimo para a disciplina. Outro agravante para que 0 ensino de Ciências fique à espera de uma ação pedagógica 
pertinente é que, no município investigado, boa parte dos professores está responsável em ministrar aulas de Educação Física e Ciências, dividindo seu tempo conforme o planejamento e relatado por P2: "à tarde, eu dou Educação Física e Ciências [...] e eu tenho que dividir essas duas disciplinas, entendeu?" (2019).

Os depoimentos também esclarecem que essa divisão não agrega no aprendizado do aluno, pois em uma semana o professor leciona Educação Física, na outra, o professor leciona Ciências.

P1: Eu acho que a maior dificuldade mesmo é essa questão de horário, eu acho que Ciências deveria ter um professor com 2 horas só pra ele por semana, só pra Ciências. Eu acho que Ciências ela é muito importante para ser dividida (2019).

P2: Não é duas horas de Ciências, eu tenho que dar em uma semana duas horas de Ciências, uma hora de Educação Física. Na outra uma hora de Ciências e duas horas de Educação Física, então é bem complicado (2019).

P9: No caso seria duas vezes por semana, né só que dividido. Só que é um tempo bem curto, ainda mais eles que são pequenos, né? (2019).

P10: Hoje em dia é assim: a gente tem que trabalhar com Ciências e Educação Física. Dá uma aula semanal de cada um (2019).

Os professores compreendem o quanto é curto o tempo cronológico para ensinar os conteúdos de Ciências; que a divisão prejudica o aprendizado do aluno e que seria de extrema importância que essas aulas fossem ministradas por professores com formação específica; que é significativo ao professor não dividir a disciplina; e o quanto é valioso ter aula de Ciências toda semana. Mas, da mesma forma, entendem que lecionar as disciplinas em alternância durante a semana, não contribui para a boa formação dos alunos.

Indo ao encontro da questão diretriz desta investigação e pensando nas compreensões que os professores apresentam sobre a disciplina nos anos iniciais, inseguranças persistem: os professores teriam condições de ministrar essa diversidade de conteúdo e inserir os alunos em uma mais integrada à ciência, mesmo com impasses ao ensinar?

Brandi e Gurgel (2002), Ramos e Rosa (2008) e Malacarne e Strieder (2009) aconselham ser necessária a renovação do ensino de Ciências nos anos iniciais e uma formação voltada à cientificidade dos professores, pois há uma preocupação com a formação integral dos alunos. É preocupante a formação desses professores, já que muitos deles são formados em Pedagogia e, em alguns casos, as universidades não suprem a habilidade em ensinar as ideias inerentes às Ciências, tal como explicitam Delizoicov e Slongo (2011) e Geglio (2015), direcionando os cursos de formação para 0 egresso do aluno na escola e no ensino da leitura e escrita. Com a falta, os professores se prendem aos livros didáticos, não realizam atividades diferenciadas em sala e transformam as aulas em meras reproduções de conteúdo.

Apesar das considerações dos autores citados, pondera-se nos depoimentos que os professores buscam trabalhar a disciplina como conseguem. Demonstram que relacionar a Ciências com outras disciplinas é complexo e que a escola não apresenta uma estrutura adequada, dificultando 0 desenvolvimento de aulas mais dinâmicas e envolvimento dos alunos. Isso fica registrado nos depoimentos, ilustrado aqui pela fala de P. 9: "o material é mais livros didáticos né? E daí algumas coisas que a gente tenta trazer pra sala, mas não tem. Que nem, digamos, ter uma sala própria pra pesquisa, né? Muitas escolas têm, a nossa já não tem. Tem bastante dificuldade" (2019). 
Porém, com todas as adversidades existentes é notório que os professores buscam ampliar possibilidades de aprendizagem baseadas num ensino que não se paute apenas na explicação de conteúdo, procurando valer-se de instrumentos ilustrativos, como imagens, revistas, vídeos, diversificando recursos para ensinar.

P5: É, eu vou a partir de experimentos e exemplos[...]. Eu até tenho ele ali. A gente fez, eu expliquei a matéria, fiz o diafragma com eles e daí eles manuseavam...eles, legal. Tá que a gente montou e desmontou e depois mostrou tudo de novo e eles puxavam a bexiga e gostaram bastante quando eles viram como era o processo do pulmão ali pro ar entrar, eles gostaram muito. É, não só a parte teórica, mas ter uma prática ali eles gostam bastante e é um jeito deles pegarem bem a matéria (2019).

Outras compreensões se revelam. Neste caso, os professores compreendem que para ensinar Ciências nos anos iniciais ( $1^{\circ}$ e $2^{\circ}$ ciclos) é preciso trabalhar com o lúdico, com ferramentas que agucem os sentidos dos alunos, como desenhos, músicas, teatros, vídeos, jogos, dentre outros: "ah, então a gente precisa muito do lúdico, né, de imagem, vídeos para conseguir transmitir o que tem no currículo" (P2, 2019). Essas ações também se destacam nas atividades diárias de outros professores: "na prática passo algumas atividades, que nós trabalhamos, o lixo reciclável, né, com $02^{0}$ ano. A gente trabalhou sucatas, material reciclável, eles montaram brinquedos, algumas coisas assim. Bastante atividades na prática mesmo" (P9, 2019).

Alguns professores relatam dificuldades para trabalhar conteúdos de Ciências, quando estes estão relacionados com 0 ensino de crianças dos primeiros ciclos. No entanto, na DCE-PR (2008) e nos PCN (1997) há a orientação de que os professores devem buscar muitas possibilidades para que 0 aluno compreenda os conteúdos. Quando 0 aluno não sabe ler (como é 0 caso dos primeiros ciclos) é possível buscar desenhos, vídeos para que lidem/interajam/pensem a respeito com os conceitos em apresentação. Isso mostra que os professores ainda não se deram conta das orientações que abrem essa possibilidade de ensinar Ciências sem que o aluno esteja alfabetizado. Neste caso, Bizzo (2002, p. 65) afirma:

Embora muitos avanços possam e devem ser realizados na área de formação de professores, os materiais de apoio ao trabalho na sala de aula são muito necessários. 0 grande desafio para o professor é decidir quais materiais adequados e de que forma podem ser utilizados. Existe uma ampla gama de materiais à disposição do professor que podem contribuir para a melhoria de seu trabalho, que inclui livros didáticos, paradidático, vídeos, softwares, etc.

No entanto, enquanto P7 (2019) relata que não há possibilidades de trabalho com alunos não alfabetizados, afirmando que "são crianças e a gente não tem o que fazer com eles, né?". P8, P9 e P11 apresentam alternativas interessantes de como ensinar Ciências sem ter como pré-requisito, leitura e escrita. Uma das ideias é buscar estratégias de ensino em aulas práticas, também entendidas aulas experimentais, tais como observamos nas próximas asserções.

P8: Então a compreensão hoje que eu entendo que você tem que focar também na prática, não só teoria [...]. A criança se motiva mais, a criança ela tem uma alegria a mais para 0 aprendizado (2019). 
P9: Olha eu ensino tipo na prática né, algumas coisas na prática (2019).

P11: Ciências ela traz bastante experiência para as crianças fazerem, desde os animais há experiências assim, como posso dizer? Fazer com a mão ali ele está trabaIhando e tal (2019).

Os professores compreendem que a utilização de materiais manipuláveis facilita 0 conhecimento dos alunos em sala de aula. Compreendem a importância de realizarem experimentos/atividades práticas em sala, pois é algo visível, que tem o poder de envolver o estudante naquele momento. Compreender 0 valor de uma aula prática para a formação dos alunos faz com que se sintam motivados a estudar os conteúdos de Ciências e enfrentarem as complexidades de aprender a aprender para ensinar.

As expressões dos professores encontram eco nos estudos de Bueno e Kovaliczn (2008) e Santos et al. (2011), que esclarecem ser 0 experimento um recurso que auxilia os alunos a buscarem e verificarem as informações dos fenômenos em sua volta. Além disso, abre a oportunidade de estabelecer relações com a teoria e a prática, resolvendo problemas e desafios para a construção de novas hipóteses.

Outro fator que nos chamou atenção ao longo das entrevistas foi a relação de dependência do professor para com o livro didático. Observamos que mesmo aqueles que buscam trabalhar de forma lúdica, revelam um uso excessivo do livro didático. P4 corrobora o que sinalizamos ao afirmar: "ah, eu procuro nos livros, né? [...] seguindo o planejamento e procurando nos livros e explico lá. Passo um textinho e umas perguntas. Eu estou ensinando eles a interpretar, é assim, segue o livro. Você tem que pesquisar" (P4, 2019).

0 emprego do verbo seguir, no dito pelo professor, revela muito mais do que um mero roteiro a ser seguido. Aponta uma prática comum dos professores do município em seguir o planejamento que já vem pronto da secretaria de educação, priorizando a sequência do livro didático. Tal depoimento chama a atenção para a seguinte inquietação: 0 que a LDB explicita sobre a formação deste professor que leciona Ciências nos anos iniciais? 0 Art. 62. Deixa claro que a formação do docente para atuar na Educação Básica "far-se-á em cursos de licenciatura em nível superior, em curso de licenciatura, de graduação plena, em universidades e institutos superiores de educação, admitida" (BRASIL,1996, p. 26).

Pelo que os depoentes disseram, eles trabalham com Ciências sem estudos específicos que favoreçam o ensino. A fragilidade formativa evidenciada, acaba gerando certa dependência por partes desses professores em relação ao material de apoio e ao planejamento curricular. Essa hipótese é reforçada por diversos depoimentos em que os professores fazem menção de que o planejamento curricular de Ciências "vem pronto" da Secretaria de Educação, a exemplo do dito de P3.

P3: Então ele vem no planejamento que a secretaria de educação manda pra gente, primeiro, segundo, terceiro e quarto bimestre e vem separado lá o que a gente tem que trabalhar. Ele vem bem assim, separado. Cada coisa, cada ano trabalha cada coisa. Sistema solar, no outro ano já...Que nem nós $05^{\circ}$ ano, a gente começou tudo, desde células e de sistemas, o último é os sentidos que tem lá para trabalhar no $4^{0}$ ano (2019).

As compreensões neste momento nos guiam para mais uma inquietação. 0 planejamento "vir pronto" contempla 0 trabalho do professor em qual aspecto do ensino na disciplina de Ciências? Fomos buscar respostas nas DCE-PR (2008) que nos informa o quão necessário é seguir pontos fundamentais para 0 professor se organizar quando for lecionar Ciências nas primeiras etapas da 
educação básica. A regionalidade coloca em xeque o planejamento já pronto. Isso está definido neste documento ao inferir que "no Plano de Trabalho Docente esses conteúdos básicos devem ser desdobrados em conteúdos específicos a serem abordados pelos professores de Ciências em função de interesses regionais e do avanço na produção do conhecimento científico" (PARANÁ, 2008, p. 67).

Com a reformulação da BNCC foi dada ênfase em Ciência e Tecnologia (C\&T) e o vínculo com a sociedade contemporânea. Isso acontece pelo fato do desenfreado desenvolvimento tecnológico e científico em que o mundo se encontra. Desse modo, no decorrer do Ensino Fundamental, a disciplina de Ciências tem como compromisso desenvolver o Letramento científico, que auxilia na compreensão e interpretação do mundo (BRASIL, 2018).

0 que mais chama a atenção é 0 destaque da C\&T. Essas competências mostram 0 quanto a C\&T não podem ser dissociadas e reforça a importância de se utilizar diversas fontes de informação para a aquisição e construção do conhecimento. Porém, na análise do dito pelos professores, esse assunto parece estar distante do dia a dia escolar ou pouco significativa, fragilizando o processo de formação escolar desde os anos iniciais. Sendo assim, que ações devem ser desenvolvidas para a inserção da C\&T na Educação Básica nesta região da investigação? Como se encontra o ensino de C\&T nos anos iniciais na rede pública do Estado do Paraná?

Fica evidente 0 quanto é necessário ter cautela para com o planejamento. Há a percepção também que, nos depoimentos, os professores não argumentam sobre C\&T. Essa asserção ocorre pelo fato de os professores direcionarem a disciplina para a alfabetização, falta de afinidade, planejamento extenso e até mesmo pela organização da disciplina: semana sim, semana não.

\section{CONSIDERAÇÕES FINAIS}

No encontro com os professores participantes do estudo foi possível realizar aproximações e distanciamentos entre 0 vivido na sala de aula e as explorações de pesquisadores que estudam 0 tema. Neste momento de ir-à-coisa-mesma, no encontro pesquisadores-professores, os pensamentos voltavam-se aos pesquisadores da área e o que revelavam sobre 0 ensino de Ciências nos anos iniciais, questionando: 0 que pesquisadores dizem sobre essas mudanças e de que forma elas inovaram 0 ensino da disciplina? Qual foi a novidade trazida para a função desse profissional que atua como mediador do conhecimento científico na disciplina escolar de Ciências?

Em busca de respostas para tais inquietações e, ao visitar a literatura tendo como guia a interrogação "que compreensões o professor dos anos iniciais tem sobre Ciências e seu ensino?" foi possível constatar mudanças significativas no ensino de Ciências como disciplina curricular nas últimas décadas. Observamos que para acompanhar esse desenvolvimento do letramento científico é apresentada competências específicas para a disciplina de Ciências para o Ensino Fundamental.

A implementação de Eixos Temáticos e os PCN resultaram em uma estrutura mais aberta à organização dos conteúdos conforme necessidades específicas, o que também auxilia na organização curricular. A obrigatoriedade do ensino da disciplina em todas as etapas do Ensino Fundamental foi outro aspecto importante a ser destacado. Isso mostra que existe uma preocupação em consolidar 0 ensino de Ciências na estrutura curricular e consequentemente garantir que tal disciplina escolar esteja presente nas salas de aulas, principalmente nos anos iniciais.

Compreendemos também, que os autores concordam que a disciplina de Ciências possa ser ensinada nos anos iniciais, e principalmente, é possível estabelecer um vínculo com os fenômenos cotidianos vivenciados pelos alunos. Os autores enfatizam diversas vezes que essa construção se 
inicie nos primeiros anos de escolarização pela alfabetização científica. Para isso, é importante que as aulas sejam lúdicas, pautadas nos saberes prévios dos alunos, o que não pode ser confundido com ensino pautado em pré-requisitos.

No encontro com o professor que ensina Ciências nos anos iniciais, estes explicitam compreensões sobre o fenômeno Ciências-e-seu-ensino-nos-anos-iniciais, quando focam seus modos de compreender 0 ensino, no que segue:

a) 0 quadro docente para ensinar Ciências nos anos iniciais não conta com professores especializados. Assim, tatear 0 ensino, se orientando pelos textos didáticos publicados por editoras comerciais tem sido o encaminhamento metodológico mais encontrado;

b) Devido aos alunos apresentarem dificuldade de leitura, escrita e nas operações básicas, os professores preferem dar mais atenção a esse aspecto da alfabetização, focando no que entendem ter maior importância: Língua Portuguesa e Matemática. Talvez esta atitude seja, também, uma válvula de escape para não se confrontar com as complexidades de ensinar algo que não se tenha conhecimento de conteúdo e pedagógico;

c) 0 planejamento escolar, que vem pronto da Secretaria de Educação, é muito extenso e algumas vezes os livros não condizem com o tema proposto, fugindo da realidade de algumas escolas, pois mesmo sendo no mesmo município cada escola tem suas particularidades;

d) A maior parte dos professores entrevistados, pedagogos, são responsáveis por ministrar aulas de Educação Física e Ciências, dividindo seu tempo conforme é estruturado o planejamento, entre dois campos do saber, que se revezam semanalmente;

e) Os professores, em sua grande maioria, buscam estratégias de ensino em aulas práticas, entendidas como experimentais e compreendem que utilizar materiais manipuláveis facilita 0 conhecimento dos alunos;

f) Em nenhum depoimento os professores chegam a argumentar sobre Ciência e Tecnologia. As falas revelam que esses professores que têm ensinado Ciências no município investigado estão imersos num mar de desafios. Lutam para vencer as ondas enviadas pelas políticas públicas educacionais, sem entender muito para onde devem remar. Assim, fazem escolhas que julgam pertinentes, contornado ou esbarrando levemente no trabalho em prol alfabetização cientifica dos alunos, por não darem conta dela nem para si.

Ao escutar atentamente os depoimentos, os professores diziam dos modos pelos quais compreendem 0 ensino de Ciências nos anos iniciais, e o mais interessante, as experiências vividas e as condições que enfrentam no cotidiano da escola que revelam que o professor está em um movimento constante de se tornar professor que ensina Ciências nos anos iniciais. Essas experiências vividas nos propõem apresentar alguns aspectos no intuito de minimizar a defasagem apresentada, trazendo, contudo, outros questionamentos que se formam a partir das situações elencadas:

1. Seria importante que áreas tão distintas, com exigências particularizadas, como Ciência e Educação Física, não fossem tratadas sem pensar seu significado para a formação das pessoas. Um primeiro passo seria admitir docentes com formação específicas nos mais diversos campos dos saberes. Uma primeira ação seria ter um professor regente, que acompanhasse integralmente as turmas e, em conjunto com professores especializados, realizassem a tessitura do ensino. Mas, onde encontrar esses professores especializados? Um caminho promissor estaria na estruturação de uma licenciatura que enlaçasse aspectos gerais dos anos iniciais, especializando o docente para 0 ciclo de alfabetização, oportunizando-o aprofundar-se em um ramo de conhecimento. 
2. Seguindo os passos da formação inicial, o formar-se permanente para ensinar deveria estar na linha de frente de qualquer política pública educacional. 0 aperfeiçoamento no ensino de Ciências necessita contar com professores formados nas licenciaturas específicas - Biologia, Química e Física. Mas, como conduzir o processo contínuo de formação do professor dos anos iniciais se estes formadores não necessariamente tiveram em suas graduações estudos voltados a essa etapa escolar? Uma abertura seriam as licenciaturas contemplarem em seus currículos estudos sobre os anos iniciais;

3. Compreendemos que Ciências nos anos iniciais, assim como outras disciplinas escolares participam do movimento para a alfabetização das crianças. Daí a importância de trabalho escolar docente integrador. É de grande valia que o gestor responsável tenha uma pauta com todos os projetos a serem desenvolvidos na escola, apresentando as melhorias necessárias em cada disciplina. Mas como fazer? Acreditamos que na estreita ligação escola-universidade podem surgir projetos transformadores, sustentados pelas pesquisas nos lócus da ação educativa.

\section{REFERÊNCIAS}

ANDRADE, S. P. ; MOCROSKY, L. F. Alfabetização e ciclo de aprendizagem: compreensões dialogadas. TEMPORIS [AÇÃO], v. 18, p. 113-134, 2018.

BATISTA, J. de 0., MOCROSKY, L. F.; MONDINI, F.. Modos de Ser na/da Educação a Distância. Ead em Foco, [S.L.], v. 10, n. 1, p. 1-14, 5 abr. 2020. Fundacao CECIERJ. http://dx.doi.org/10.18264/eadf.v10i1.901.

BICUDO, M. A. V. Pesquisa qualitativa e a abordagem fenomenológica: o percurso da professora pesquisadora Maria Aparecida Viggiani Bicudo. ACTI0, Curitiba, v. 3, n. 3, p. 236-252; Seção Entrevistas; set./dez. 2018.

BICUD0, M. A. V. Pesquisa qualitativa segundo a visão fenomenológica. 1ªed. São Paulo: Editora Cortez, 2011.

BIZZO, N. . Ciências: fácil ou difícil. São Paulo: Ática, 2002.

BRANDI, A. T. E.; GURGEL, C. M. A. A alfabetização científica e o processo de ler e escrever em séries iniciais: emergências de um estudo de investigação-ação. Ciências \& Educação, Brasília, v. 8, n. 1, p. 113-125, 2002. Disponível em: Acesso em jul. 2018.

BRASIL. Lei 5.692, de 11 de agosto de 1971. Fixa Diretrizes e Bases para 0 ensino de $1^{\circ}$ e $2^{\circ}$ graus, e dá outras providências. Brasília, DF: 1971. Disponível em: https://bit.ly/2Zd47Rz. Acesso em ago. 2018.

BRASIL. Base Nacional Comum Curricular: Educação Infantil e Ensino Fundamental. Brasília: MEC/Secretaria de Educação Básica, 2017.

BRASIL. Secretaria de Educação Fundamental. Parâmetros Curriculares Nacionais: Ciências Naturais. Brasília, DF: MEC/SEF, 1998.

BRASIL. Parâmetros curriculares nacionais: Ciências naturais. Secretaria de Educação Fundamental. - Brasília: MEC/SEF, 1997.

BRASIL. Lei $\mathbf{n}^{0}$. 9.394, de 20 de dezembro de 1996. Lei de Diretrizes e Bases da Educação Nacional. Brasília, DF: 20 de dezembro de 1996. 
BRASIL. Lei 4.024, de 20 de dezembro de 1961. Fixa as Diretrizes e Bases da Educação Nacional. Brasília: DF. 1961. Disponível em: https://bit.ly/3IOXiNX. Acesso em: ago. 2018.

BUENO, R. S. M.; KOVALICZN, R. A. 0 ensino de Ciências e as dificuldades das atividades experimentais. 2008. p. 18-19. Disponível em: https://bit.ly/3ksM0iU. Acesso em: jul. 2018.

CARVALHO, A.M.P. 1997. Ciências no Ensino Fundamental. Caderno de Pesquisa 101: 152-168. Jul. 1997

DELIZOICOV, N. ; SLONGO, I. I. P. 0 Ensino de Ciências nos anos iniciais do Ensino Fundamental: elementos para uma reflexão sobre a prática pedagógica. Série-Estudos, v. 1, p. 205 - 221; 2011.

DUCATTI-SILVA, K. C. A formação no curso de pedagogia para 0 ensino de Ciências nas séries iniciais. 2005. 222f. Dissertação (Mestrado em Educação) - Faculdade de Filosofia e Ciências, Universidade Estadual Paulista, Marília, 2005.

FABRI, F.; SILVEIRA, R. M. C. F. Alfabetização científica e tecnológica nos anos iniciais a partir do tema lixo tecnológico. Revista Brasileira de Ensino de Ciências e Tecnologia, Ponta Grossa, v. 5, n. 2, p. 99-127, 2012.

FILHO, A. B. S. SANTANA, J.R.S. CAMPOS, T.D. 0 ensino de Ciências naturais nos anos iniciais do Ensino Fundamental: relevância e possibilidade. In: V Colóquio Internacional - Educação e Contemporaneidade. Eixo Temático: Educação e Ensino de Ciências Humanas e Sociais, 2012.

FINI, M. I. Sobre a pesquisa qualitativa em educação que tem a fenomenologia como suporte. In: BICUDO, M. A. V. ; ESPOSITO, V. H. C. (Org.). A pesquisa qualitativa em educação: um enfoque fenomenológico. p. 23-33. Piracicaba: Unimep, 1994.

FUMAGALLI, Laura. 0 ensino de Ciências naturais no nível fundamental de educação formal: argumentos a seu favor. In: WEISSMANN, Hilda (Org.). Didática das Ciências naturais: contribuições e reflexões, Porto Alegre: ArtMed, 1998.

GEGLIO, P. C. ensino de Ciências nos anos iniciais do Ensino Fundamental: a procura pela interdisciplinaridade nas práticas de professoras polivalentes. Didática e Prática de Ensino na relação com a Escola. EdUECE- 2015.

GOLDEMBERG, José. 0 repensar a educação no Brasil. Estudos Avançados, São Paulo, v. 7, n. 18, p. 65-137, 1993.

HEIDEGGER, M. Heráclito: a origem do pensamento ocidental: lógica: a doutrina heraclítica do lógos. Tradução de M. S. C. Schuback. Rio de Janeiro: Relume Dumará, 1999.

LORENZETTI, L. Alfabetização científica no contexto das séries iniciais. 2000. 143 f. Dissertação (Mestrado em Educação) - Centro de Ciências da Educação, Universidade Federal de Santa Catarina, Florianópolis-SC, 2000. Disponível em: https://bit.ly/3kpsnrY. Acesso em: maio. 2018.

KRASILCHIK, M. Reformas e realidade: o caso do ensino de Ciências. São Paulo em Perspectiva. v. 14, n. 1. São Paulo Jan. /Mar. 2000, p. 85-93.

MALACARNE, V. ; STRIEDER, D.M. 0 desvelar da Ciências nos Anos Iniciais do Ensino Fundamental: um olhar pelo viés da experimentação. Revista Eletrônica Vivências. Rio Grande do Sul. v. 5, n. 7, p. 75-85, mai. 2009. Disponível em: https://bit.ly/3tX48V7. Acesso em: Jan. 2018. 
PARANÁ. Secretaria de Estado da Educação. Diretrizes Curriculares de Ciências para a Educação Básica. Curitiba, 2008.

RAMOS, L. B. da C.; ROSA, P. R. da S. 0 ensino de Ciências: fatores intrínsecos e extrínsecos que limitam a realização de atividades experimentais pelo professor dos anos iniciais do Ensino Fundamental. Investigações em Ensino de Ciências, v. 13, n. 3, p. 299-331, 2008.

SANTOS, A. C. CANEVER, C. F. GIASSI, M. G. A importância do ensino de Ciências na percepção de alunos de escolas da rede pública municipal de criciúma - SC, Revista Univap, São José dos Campos-SP: v. 17, n. 30, dez.2011

SILVA, D.C.G. Desafios de ensinar Matemática na Educação Básica: um estudo com professores no início de carreira. Dissertação de Mestrado em Educação de Ciências e Matemática. Universidade Federal do Paraná - Curitiba - Paraná, 2018.

STOLL, V. G.; BICA, A. C.; COUTINHO, C.; OSÓRIO, T. da R.. REVISTA DO ENSINO/RS (1951-1961): um olhar histórico sobre as diretrizes da experimentação no ensino de ciências. Vidya, [S.L.], v. 41, n. 1, p. 93-112, 2021. Vidya. http:// dx.doi.org/10.37781/vidya.v4111.3506.

TOMÉ, L. M.. Ensino de Ciências nos anos iniciais: um diálogo com professores polivalentes. 2019. 149 f. Dissertação (Mestrado) - Curso de Educação em Ciências e em Matemática, Pós-Graduação em Educação em Ciências e em Matemática, Universidade Federal do Paraná, Curitiba, 2019.

RECEBIDO EM: 20 abr. 2021

CONCLUÍDO EM: 30 ago. 2021 
